\title{
Complications of Volar Plating of Distal Radius Fractures: A Systematic Review
}

\author{
Todd H. Alter, BS ${ }^{1} \quad$ Kristin Sandrowski, MD ${ }^{1}$ Gregory Gallant, MD ${ }^{1}$ Moody Kwok, MD ${ }^{1}$ \\ Asif M. Ilyas, $\mathrm{MD}^{1}$
}

${ }^{1}$ Department of Hand and Wrist Surgery, Rothman Institute at the Thomas Jefferson University, Philadelphia, Pennsylvania

Address for correspondence Todd H. Alter, BS, Rothman Institute at the Thomas Jefferson University, 925 Chestnut Street, Philadelphia,

J Wrist Surg 2019;8:255-262. PA 19107 (e-mail: todd.alter@jefferson.edu).

\begin{abstract}
\section{Keywords}

- distal radius fracture

- volar locking plate

- complications

Background In recent years, there has been an increased utilization of volar locking plate fixation of distal radius fractures (DRFs). However, reported long-term complication rates with this technique remain unclear.

Purpose The purpose of this systematic review was to investigate the pooled incidence of complications associated with volar locking plating of DRF.

Methods A search of the Scopus database was performed from 2006 through 2016. Studies were considered eligible if they had a diagnosis of a DRF and were treated with a volar locking plate with an average of 12 months or longer follow-up.

Results The literature search yielded 633 citations, with 55 eligible for inclusion in the review (total $n=3,911$ ). An overall complication rate of $15 \%$ was identified, with $5 \%$ representing major complications requiring reoperation. The most common complication types identified included nerve dysfunction (5.7\%), tendon injury (3.5\%), and hardware-related issues (1.6\%).

Conclusion Nerve complications were reportedly higher than tendon and hardwarerelated complications combined. However, despite varying complication rates in the literature, this systematic review reveals an overall low complication rate associated with volar locking plating of DRF.
\end{abstract}

Distal radius fractures remain one of the most common orthopaedic injuries. ${ }^{1-3}$ However, despite this high incidence, there remains no consensus regarding the optimal treatment strategy. Common treatment options currently include closed reduction, closed reduction with percutaneous pinning, intramedullary fixation, external fixation, and various open reduction and internal fixation strategies. ${ }^{4-7}$ Despite the various available treatment strategies, open reduction and internal fixation with dorsal and volar plates has seen a steady increase in use in recent years due to purported faster functional recovery and often improved radiographic alignment. ${ }^{4,8,9}$ In particular, over the last decade there has been an increased utilization of volar locked plating of distal radius fractures. ${ }^{5,8,10-12}$

received

April 16, 2018

accepted

June 15, 2018

published online

August 13, 2018
The most commonly reported complications with this technique can be divided into the following categories: nerve related, tendon related, and hardware related. Carpal tunnel syndrome is the most common nerve-related complication, although this frequently occurs with distal radius fracture regardless of treatment modality. ${ }^{13}$ Vulnerable tendons with volar locking plates include both extensor tendons (extensor pollicis longus, extensor digitorum communis, extensor indicis) $^{14,15}$ and flexor tendons (flexor pollicis longus, flexor digitorum profundus), ${ }^{16}$ with purportedly lower overall rates compared with dorsal plates. ${ }^{17}$ Hardware-related complications include malunion, screw loosening, and loss of reduction, among others. In addition, complications such as infection, hematoma, and wound dehiscence can occur with

Copyright $\odot 2019$ by Thieme Medical Publishers, Inc., 333 Seventh Avenue, New York, NY 10001, USA.

DOI https://doi.org/ 10.1055/s-0038-1667304. ISSN 2163-3916. 
any surgical procedure, as well as many other less frequently reported sequelae.

In spite of the rising utilization of this technique, our understanding of long-term complication rates associated with volar locking plating of distal radius fractures remains limited. Therefore, the purpose of this study was to perform a systematic review to investigate incidence of complications following volar locking plate fixation of distal radius fractures.

\section{Methods}

A search of the Scopus database, which incorporates PubMed and Medline, was performed from 2006 through 2016. This timeframe was selected to focus on a period where specifically locked, rather than nonlocked, volar plating was more ubiquitous. The database was searched using the following search terms: volar, palmar, Colles fracture, Barton fracture, Smith fracture, distal radius fracture, distal radial fracture, or fracture of distal radius. Only articles written in English were included.

Studies were considered eligible if they met the following criteria: (1) patients had a diagnosis of a distal radius fracture, irrespective of diagnostic criteria, etiology, associated pathology, sex, or age; (2) patients were treated with a volar locking plate. Studies were excluded if they were (1) case reports; (2) reviews; (3) animal studies; (4) cadaveric studies; (5) complication data unavailable or not presented; (6) inadequate plate-type information; (7) dorsal plate fixation; (8) additional percutaneous pin fixation augmentation; (9) nonlocking volar plates; and (10) follow-up less than 12 months (-Fig. 1).

Each included study was independently analyzed by two different authors (T.H.A. and A.M.I.). The following data were

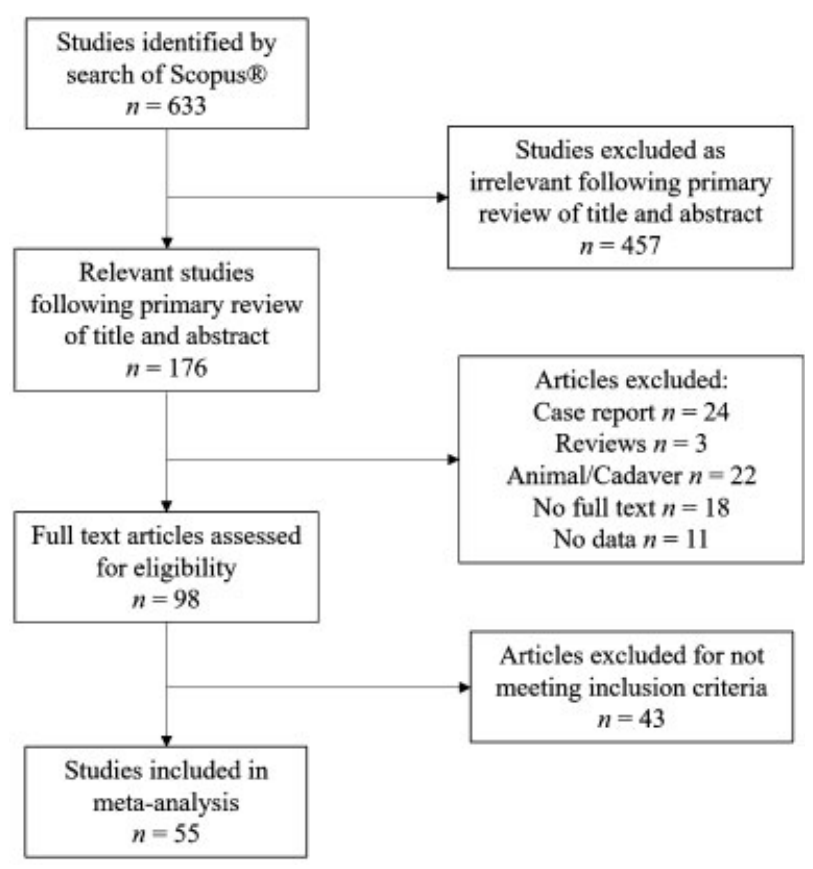

Fig. 1 Flow diagram indicating results of the literature search and study selection procedure. extracted and recorded: study characteristics (first author, year of publication, country of origin); fracture characteristics, implant type; sample size; mean age; sex distribution; duration of follow-up; study design; number of complications. A complication was defined as an adverse treatment event that was reported by the authors of the study. The main outcome measure of the systematic review was the overall rate of complications. Complications were divided into minor and major complications, with a major complication defined as any adverse event postoperatively requiring reoperation during the study follow-up period.

\section{Results}

The literature search identified 633 citations, of which 55 were eligible for inclusion in the systematic review (total $n=3,911) .4,6,9,10,13,18-67$ The average age was 57 , with a range from 13 to 94 . Men accounted for $36 \%$ of all patients. Average follow-up was 20.6 months, with a range from 6 to 90 months. The overall complication rate identified was $15 \%$. Major complications requiring reoperation accounted for $5 \%$, and minor complications consisted of $10 \%$ (-Table 1 ).

The most common complications included nerve dysfunction (5.7\%), tendon injury (3.5\%), and hardware problems (1.6\%; - Table 2). Other complications in descending order of incidence included infection, wound complications, and refracture or loss of reduction accounting for 3.9\%. A major complication was defined as one requiring reoperation, with the exception of carpal tunnel syndrome, complex regional pain syndrome, and plate removal by patient request. The most common major complication was tendon rupture, with extensor being more common than flexor tendon rupture (-Table 3).

Nerve complications were most common with an overall rate of $5.7 \%$, with postoperative carpal tunnel syndrome being the most common at $2 \%$. Complex regional pain syndrome was reported in $1.4 \%$ of cases.

The overall tendon complication rate was 3.5\% with extensor tendon rupture accounting for $1 \%$ and extensor tenosynovitis $0.6 \%$. Flexor tendon tenosynovitis and rupture were reportedly lower at 0.7 and $0.3 \%$, respectively. De Quervain's tenosynovitis, intersection syndrome, and trigger finger were equally low at $0.03 \%$ overall. The incidence of tendonitis and tendon rupture where the tendon was not specified was 0.7 and $0.1 \%$, respectively.

Hardware complication rate was $1.6 \%$, with malunion being the most common at $0.6 \%$. Plate prominence was encountered in only $0.1 \%$ of patients, screw loosening in $0.3 \%$, intra-articular screws in $0.2 \%$, and prominent screws in $0.1 \%$.

\section{Discussion}

The purpose of this study was to perform a systematic review to investigate incidence of complications following volar locking plate fixation of distal radius fractures. Despite the varying overall complication rates in the literature from 0 to $60 \%, 4,6,9,10,13,18-67$ this systematic review reports an overall complication rate of $15 \%$ associated with volar locked plating of distal radius fractures, of which only $5 \%$ were considered 


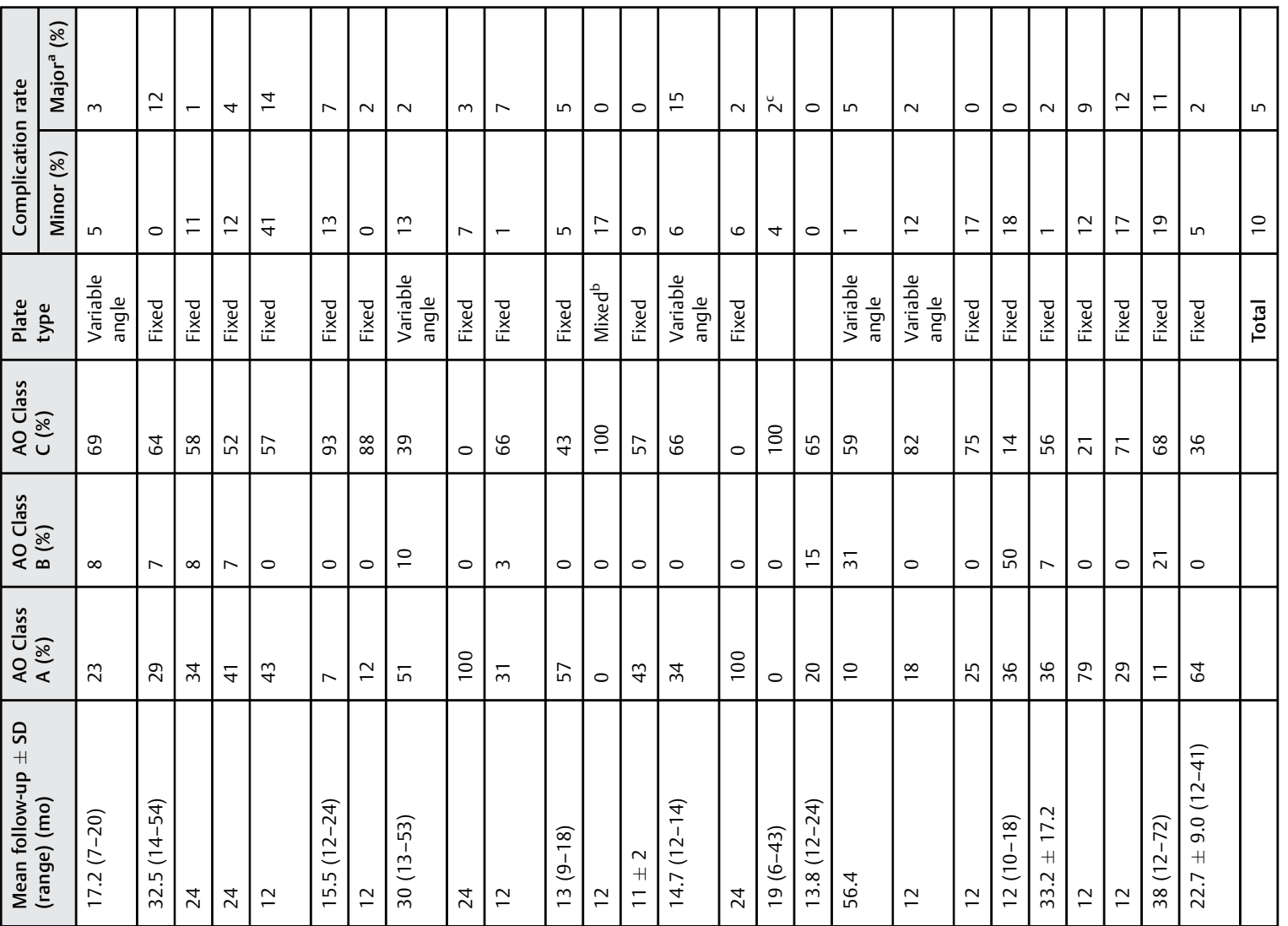

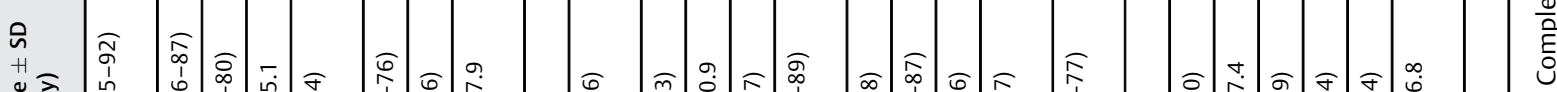

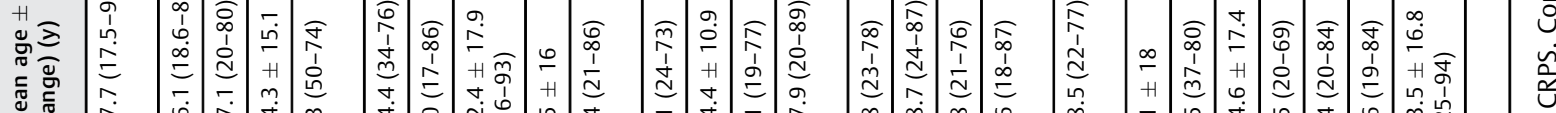



$\leftarrow \stackrel{\frac{n}{ \pm}}{\underline{\omega}}$

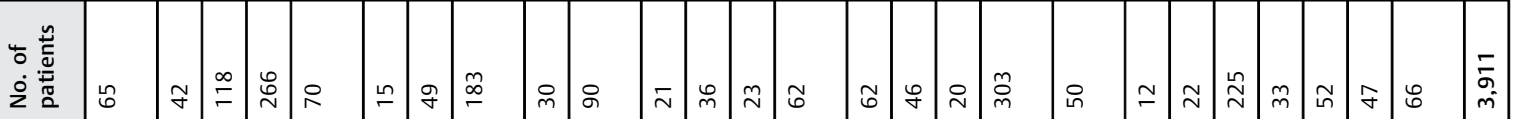

尝

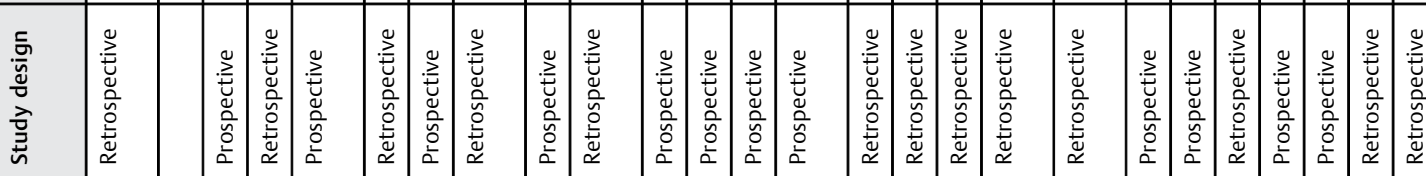

\begin{tabular}{|c|c|c|c|c|c|c|c|c|c|c|c|c|c|c|c|c|c|c|c|}
\hline 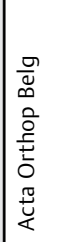 & 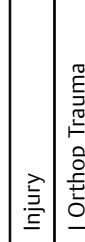 & 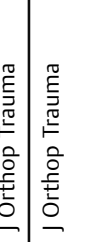 & 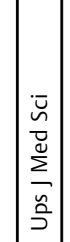 & 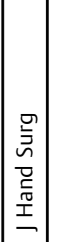 &  &  & 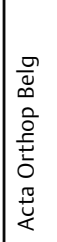 & 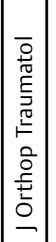 & 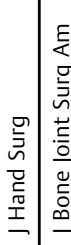 &  & 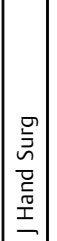 & 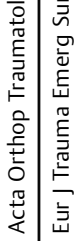 & 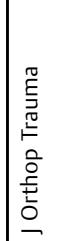 & 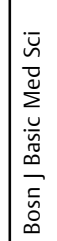 & 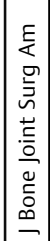 &  & o & & 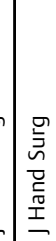 \\
\hline $1=$ & $\overline{\bar{\nu}} \overline{\bar{\nu}}$ & 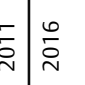 & $\bar{\sim}$ & \begin{tabular}{|l|} 
\\
$\stackrel{\infty}{0}$ \\
$\stackrel{\sim}{~}$ \\
\end{tabular} & $\stackrel{\sim}{\stackrel{N}{N}}$ & $\tilde{\sim}$ & 商 & $\overline{\dot{\nu}}$ & 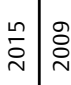 & 产 & 号 & \begin{tabular}{l|l}
$\stackrel{\sim}{\tilde{N}}$ & $\tilde{i}$ \\
$\stackrel{i}{n}$
\end{tabular} & $\stackrel{m}{\stackrel{n}{n}}$ & $\dot{\sim}$ & $\stackrel{N}{N}$ & & 1 & $\stackrel{m}{\stackrel{m}{n}}$ & $\bar{\sim}$ \\
\hline
\end{tabular}

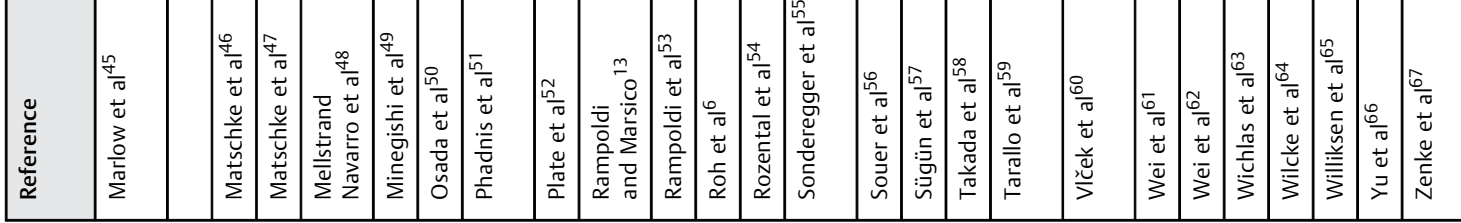


Complications of Volar Plating of DRF Alter et al. 259

Table 2 Most common complications

\begin{tabular}{|l|l|}
\hline Complication type & Rate (\%) \\
\hline Nerve & 5.70 \\
\hline Carpal Tunnel Syndrome (CTS) & 2.05 \\
\hline Complex Regional Pain Syndrome (CRPS) & 1.41 \\
\hline Median nerve sensitivity (no CTS) & 1.25 \\
\hline Paresthesia (nonspecific) & 0.38 \\
\hline Radial nerve neuropathy & 0.20 \\
\hline Median nerve damage (thenar motor) & 0.15 \\
\hline Paresthesia (thenar region) & 0.13 \\
\hline Paresthesia (cutaneous branch) & 0.10 \\
\hline Ulnar nerve neuropathy & 0.03 \\
\hline Tendon & 3.53 \\
\hline Extensor tendon rupture & 1.02 \\
\hline Flexor tenosynovitis & 0.69 \\
\hline Tendonitis (nonspecific) & 0.69 \\
\hline Extensor tenosynovitis & 0.59 \\
\hline Flexor tendon rupture & 0.33 \\
\hline Tendon rupture (nonspecific) & 0.13 \\
\hline Intersection syndrome & 0.03 \\
\hline De Quervain & 0.03 \\
\hline Trigger finger & 0.03 \\
\hline Hardware & 0.61 \\
\hline Malunion & 0.61 \\
\hline Screw loosening & 0.33 \\
\hline Loss of reduction & 0.23 \\
\hline Intra-articular screw & 0.20 \\
\hline Prominent screw & 0.13 \\
\hline Prominent plate & 0.05 \\
\hline Broken plate & 0.03 \\
\hline
\end{tabular}

major complications by requiring a reoperation. Much of the discrepancy in the literature was surmised to be related to the varying definitions of a "complication," how stringent complications were reported by the authors, and how a major or minor complication was defined if at all. For instance, Mellstrand et al performed a randomized control trial comparing volar locked plating and external fixation with a high complication rate of $50.7 \%$ in the volar locking plate group and $44.6 \%$ in the external fixation group. ${ }^{48}$ Although only one patient who underwent volar locked plating developed carpal tunnel syndrome that was treated operatively, $36.9 \%$ of patients reported some form of nerve dysfunction. However, this nerve dysfunction was most often transient requiring no additional treatment or surgery.

As illustrated in our review, several reported series identified nerve dysfunction and/or carpal tunnel syndrome as the most common complication following volar locking plate fixation. Arora et al performed a prospective randomized
Table 3 Major complications by complication type

\begin{tabular}{|c|c|c|c|}
\hline \multicolumn{2}{|c|}{ Major complication type } & \multirow{2}{*}{$\begin{array}{l}\begin{array}{l}\text { No. of } \\
\text { events }\end{array} \\
19\end{array}$} & \multirow{2}{*}{$\begin{array}{l}\begin{array}{l}\% \text { of total } \\
\text { patients }\end{array} \\
0.49\end{array}$} \\
\hline Tendon & $\begin{array}{l}\text { Extensor } \\
\text { tenosynovitis }\end{array}$ & & \\
\hline & $\begin{array}{l}\text { Extensor tendon } \\
\text { rupture }\end{array}$ & 40 & 1.02 \\
\hline & Flexor tenosynovitis & 23 & 0.59 \\
\hline & $\begin{array}{l}\text { Flexor tendon } \\
\text { rupture }\end{array}$ & 13 & 0.33 \\
\hline & $\begin{array}{l}\text { Tendonitis } \\
\text { (nonspecific) }\end{array}$ & 8 & 0.20 \\
\hline & $\begin{array}{l}\text { Tendon rupture } \\
\text { (nonspecific) }\end{array}$ & 1 & 0.03 \\
\hline & $\begin{array}{l}\text { Tendon sheath } \\
\text { fibroma }\end{array}$ & 1 & 0.03 \\
\hline \multirow[t]{8}{*}{ Hardware } & Screw loosening & 5 & 0.13 \\
\hline & Intra-articular screw & 4 & 0.10 \\
\hline & Prominent screw & 2 & 0.05 \\
\hline & Prominent plate & 2 & 0.05 \\
\hline & Loss of reduction & 5 & 0.13 \\
\hline & Malunion & 2 & 0.05 \\
\hline & $\begin{array}{l}\text { Radioulnar } \\
\text { synostosis }\end{array}$ & 1 & 0.03 \\
\hline & Plate break & 1 & 0.03 \\
\hline \multirow[t]{3}{*}{ Other } & $\begin{array}{l}\text { Pain/Discomfort/ } \\
\text { Irritation }\end{array}$ & 39 & 1.00 \\
\hline & Infection & 1 & 0.03 \\
\hline & $\begin{array}{l}\text { Nonspecific } \\
\text { reoperations }\end{array}$ & 21 & 0.54 \\
\hline Total & & 188 & 4.81 \\
\hline
\end{tabular}

study between cast treatment and volar locked plating and reported an operative complication rate of $13 \%,{ }^{10}$ comparable to our review's rate. Further they found a $2.8 \%$ rate of carpal tunnel syndrome, similar to our combined $2 \%$. Roh et al compared volar plating and external fixation and reported a complication rate following volar plating of $17 \%$, with a rate of carpal tunnel syndrome also at $2.8 \%$, both comparable to our reported rates. ${ }^{6}$

Carpal tunnel syndrome is common and endemic in the population at large, but it is also known to occur as a product of distal radius fractures in 7 to $15 \%{ }^{68}$ of cases in general, irrespective of treatment strategy. Typically, carpal tunnel syndrome following distal radius fracture is not assumed to be related to hardware, but more related to the trauma to the nerve from the fracture and/or subsequent healing with thickened bony anatomy and any residual malunion. Due to the endemic nature, we considered carpal tunnel syndrome to be a minor complication even in instances where carpal tunnel release was required. Additionally, plate removal by patient request was not considered a complication, major or minor. However, symptomatic hardware or 
tendon irritation due to hardware is directly related to the fixation and therefore considered a major complication if reoperation was required.

It has been hypothesized that the volar anatomy of the wrist is better suited to plating than the dorsal side due to the presence of more space and less contact between the distal radial cortex and tendons. ${ }^{49}$ Our systematic review identified only $0.7 \%$ flexor tendon tenosynovitis and $0.3 \%$ flexor tendon rupture. While we did find low rates of flexor tendon involvement following volar locking plate fixation, there was an overall tendon complication rate of $3.8 \%$ with extensor tendon complications accounting for $1.9 \%$. In a systematic review of tendon complications following open reduction and internal fixation of distal radius fractures, Azzi et al similarly found a low incidence of tendon complications following volar plating. ${ }^{69}$ Their systematic review reported a 7.5 versus $4.5 \%$ tenosynovitis and 1.7 versus $1.4 \%$ tendon rupture rate following dorsal plating and volar locked plating, respectively.

Further comparison of complication rates between dorsal and volar locked plating by Wichlas et al found a low complication rate in both groups with $3.6 \%$ in the volar plate and $11.7 \%$ in the dorsal plate groups. ${ }^{63}$ They reported a low incidence of carpal tunnel syndrome at $0.44 \%$ and no tendon complications following volar locked plating. Although they found no tendon complications, implant removal was performed in $6.7 \%$ of the volar locked plate group for patients with implant-associated pain, swelling, or patient request. Whether or not persistent pain and swelling in the volar group was related to tendon irritation or truly symptomatic hardware from another source is unclear.

We found a lower hardware complication rate than expected, with the majority of complications associated with screw loosening or prominent screws. Hardware complications are likely underreported in the literature, as many nerve and tendon complication may be related to symptomatic hardware even if not explicitly stated. Arora et al found a $27 \%$ complication rate following volar locked plating with tendon complications accounting for more than half and all patients with tenosynovitis underwent early hardware removal. ${ }^{18}$ While all cases of tenosynovitis and tendon rupture may not be associated with hardware prominence, the two are likely related and may explain the lower than expected hardware complication rate in our systematic review.

The main limitation of our systematic review is the heterogeneity of the data. Different surgical approaches, implants, and techniques for volar locked plating were utilized in these studies. Further, surgeon experience likely varied. Also, the scrutiny with which complications were noted by the authors is inherently unpredictable. Despite these limitations, this meta-analysis highlights the overall complication rates associated with volar locked plating of distal radius fractures over the past 10 years.

In short, this systematic review provides an updated review of the literature demonstrating a low tendon and hardware complication rate supporting the increased utilization of volar plating, and it also identified that nerve dysfunction is prevalent. Further investigation regarding the different types of volar plates may help elucidate the reason for varying complication rates between studies.

\section{Funding}

None.

Conflict of Interest

None declared.

\section{References}

1 Court-Brown CM, Caesar B. Epidemiology of adult fractures: a review. Injury 2006;37(08):691-697

2 Karl JW, Olson PR, Rosenwasser MP. The epidemiology of upper extremity fractures in the United States, 2009. J Orthop Trauma 2015;29(08):e242-e244

3 Kilgore ML, Morrisey MA, Becker DJ, et al. Health care expenditures associated with skeletal fractures among Medicare beneficiaries, 1999-2005. J Bone Miner Res 2009;24(12):2050-2055

4 Arora R, Gabl M, Gschwentner M, Deml C, Krappinger D, Lutz M. A comparative study of clinical and radiologic outcomes of unstable Colles type distal radius fractures in patients older than 70 years: nonoperative treatment versus volar locking plating. J Orthop Trauma 2009;23(04):237-242

5 Bales JG, Stern PJ. Treatment strategies of distal radius fractures. Hand Clin 2012;28(02):177-184

6 Roh YH, Lee BK, Baek JR, Noh JH, Gong HS, Baek GH. A randomized comparison of volar plate and external fixation for intra-articular distal radius fractures. J Hand Surg Am 2015;40(01):34-41

7 Schneppendahl J, Windolf J, Kaufmann RA. Distal radius fractures: current concepts. J Hand Surg Am 2012;37(08):1718-1725

8 Chung KC, Shauver MJ, Birkmeyer JD. Trends in the United States in the treatment of distal radial fractures in the elderly. J Bone Joint Surg Am 2009;91(08):1868-1873

9 Hakimi M, Jungbluth P, Windolf J, Wild M. Functional results and complications following locking palmar plating on the distal radius: a retrospective study. J Hand Surg Eur Vol 2010;35(04): 283-288

10 Arora R, Lutz M, Deml C, Krappinger D, Haug L, Gabl M. A prospective randomized trial comparing nonoperative treatment with volar locking plate fixation for displaced and unstable distal radial fractures in patients sixty-five years of age and older. J Bone Joint Surg Am 2011;93(23):2146-2153

11 Cui Z, Pan J, Yu B, Zhang K, Xiong X. Internal versus external fixation for unstable distal radius fractures: an up-to-date metaanalysis. Int Orthop 2011;35(09):1333-1341

12 Koval KJ, Harrast JJ, Anglen JO, Weinstein JN. Fractures of the distal part of the radius. The evolution of practice over time. Where's the evidence? J Bone Joint Surg Am 2008;90(09):1855-1861

13 Rampoldi M, Marsico S. Complications of volar plating of distal radius fractures. Acta Orthop Belg 2007;73(06):714-719

14 Zenke Y, Sakai A, Oshige T, et al. Extensor pollicis longus tendon ruptures after the use of volar locking plates for distal radius fractures. Hand Surg 2013;18(02):169-173

15 Asadollahi S, Keith PP. Flexor tendon injuries following plate fixation of distal radius fractures: a systematic review of the literature. J Orthop Traumatol 2013;14(04):227-234

16 Zhao HL, Wang GB, Jia YQ, Zhu SC, Zhang FF, Liu HM. Comparison of risk of Carpal Tunnel syndrome in patients with distal radius fractures after 7 treatments. Med Sci Monit 2015;21:2837-2844

17 Fowler JR, Ilyas AM. Prospective evaluation of distal radius fractures treated with variable-angle volar locking plates. J Hand Surg Am 2013;38(11):2198-2203

18 Arora R, Lutz M, Hennerbichler A, Krappinger D, Espen D, Gabl M. Complications following internal fixation of unstable distal radius fracture with a palmar locking-plate. J Orthop Trauma 2007;21 (05):316-322

19 Brennan SA, Kiernan C, Beecher S, et al. Volar plate versus k-wire fixation of distal radius fractures. Injury 2016;47(02):372-376 
20 Chung KC, Squitieri L, Kim HM. Comparative outcomes study using the volar locking plating system for distal radius fractures in both young adults and adults older than 60 years. J Hand Surg Am 2008;33(06):809-819

21 Chung KC, Watt AJ, Kotsis SV, Margaliot Z, Haase SC, Kim HM. Treatment of unstable distal radial fractures with the volar locking plating system. J Bone Joint Surg Am 2006;88(12):2687-2694

22 Figl M, Weninger P, Jurkowitsch J, Hofbauer M, Schauer J, Leixnering M. Unstable distal radius fractures in the elderly patient-volar fixed-angle plate osteosynthesis prevents secondary loss of reduction. J Trauma 2010;68(04):992-998

23 Figl M, Weninger P, Liska M, Hofbauer M, Leixnering M. Volar fixed-angle plate osteosynthesis of unstable distal radius fractures: 12 months results. Arch Orthop Trauma Surg 2009;129 (05):661-669

24 Gruber G, Gruber K, Giessauf C, et al. Volar plate fixation of AO type $\mathrm{C} 2$ and $\mathrm{C} 3$ distal radius fractures, a single-center study of 55 patients. J Orthop Trauma 2008;22(07):467-472

25 Gereli A, Nalbantoglu U, Kocaoglu B, Turkmen M. Comparative study of the closed reduction percutaneous cannulated screw fixation and open reduction palmar locking plate fixation in the treatment of AO type A2 distal radius fractures. Arch Orthop Trauma Surg 2014;134(01):121-129

26 Gereli A, Nalbantoğlu U, Kocaoğlu B, Türkmen M. Comparison of palmar locking plate and K-wire augmented external fixation for intra-articular and comminuted distal radius fractures. Acta Orthop Traumatol Turc 2010;44(03):212-219

27 Goehre F, Otto W, Schwan S, Mendel T, Vergroesen PP, LindemannSperfeld L. Comparison of palmar fixed-angle plate fixation with K-wire fixation of distal radius fractures (AO A2, A3, C1) in elderly patients. J Hand Surg Eur Vol 2014;39(03):249-257

28 Gogna P, Selhi HS, Singla R, et al. Osteosynthesis with long volar locking plates for metaphyseal-diaphyseal fractures of the distal radius. Chin J Traumatol 2013;16(06):339-343

29 Gradl G, Mielsch N, Wendt M, et al. Intramedullary nail versus volar plate fixation of extra-articular distal radius fractures. Two year results of a prospective randomized trial. Injury 2014;45 (Suppl 1):S3-S8

30 Gradl G, Gradl G, Wendt M, Mittlmeier T, Kundt G, Jupiter JB. Nonbridging external fixation employing multiplanar K-wires versus volar locked plating for dorsally displaced fractures of the distal radius. Arch Orthop Trauma Surg 2013;133(05):595-602

31 Grewal R, MacDermid JC, King GJW, Faber KJ. Open reduction internal fixation versus percutaneous pinning with external fixation of distal radius fractures: a prospective, randomized clinical trial. J Hand Surg Am 2011;36(12):1899-1906

32 Gruber G, Zacherl M, Giessauf C, et al. Quality of life after volar plate fixation of articular fractures of the distal part of the radius. J Bone Joint Surg Am 2010;92(05):1170-1178

33 Hollevoet N, Vanhoutie T, Vanhove W, Verdonk R. Percutaneous Kwire fixation versus palmar plating with locking screws for Colles' fractures. Acta Orthop Belg 2011;77(02):180-187

34 Karantana A, Downing ND, Forward DP, et al. Surgical treatment of distal radial fractures with a volar locking plate versus conventional percutaneous methods: a randomized controlled trial. J Bone Joint Surg Am 2013;95(19):1737-1744

35 Kato S, Tatebe M, Yamamoto M, Iwatsuki K, Nishizuka T, Hirata H. The results of volar locking plate fixation for the fragility fracture population with distal radius fracture in Japanese women. Nagoya J Med Sci 2014;76(1-2):101-111

36 Kawasaki K, Nemoto T, Inagaki K, Tomita K, Ueno Y. Variable-angle locking plate with or without double-tiered subchondral support procedure in the treatment of intra-articular distal radius fracture. J Orthop Traumatol 2014;15(04):271-274

37 Khamaisy S, Weil YA, Safran O, Liebergall M, Mosheiff R, Khoury A. Outcome of dorsally comminuted versus intact distal radial fracture fixed with volar locking plates. Injury 2011;42(04): 393-396
38 Knight D, Hajducka C, Will E, McQueen M. Locked volar plating for unstable distal radial fractures: clinical and radiological outcomes. Injury 2010;41(02):184-189

39 Konstantinidis L, Helwig P, Strohm PC, Hirschmüller A, Kron P, Südkamp NP. Clinical and radiological outcomes after stabilisation of complex intra-articular fractures of the distal radius with the volar 2.4 mm LCP. Arch Orthop Trauma Surg 2010;130(06):751-757

40 Kumbaraci M, Kucuk L, Karapinar L, Kurt C, Coskunol E. Retrospective comparison of external fixation versus volar locking plate in the treatment of unstable intra-articular distal radius fractures. Eur J Orthop Surg Traumatol 2014;24(02):173-178

41 Kwan K, Lau TW, Leung F. Operative treatment of distal radial fractures with locking plate system-a prospective study. Int Orthop 2011;35(03):389-394

42 Lattmann T, Dietrich M, Meier C, Kilgus M, Platz A. Comparison of 2 surgical approaches for volar locking plate osteosynthesis of the distal radius. J Hand Surg Am 2008;33(07):1135-1143

43 Lattmann T, Meier C, Dietrich M, Forberger J, Platz A. Results of volar locking plate osteosynthesis for distal radial fractures. J Trauma 2011;70(06):1510-1518

44 Lee YS, Wei TY, Cheng YC, Hsu TL, Huang CR. A comparative study of Colles' fractures in patients between fifty and seventy years of age: percutaneous K-wiring versus volar locking plating. Int Orthop 2012;36(04):789-794

45 Marlow WJ, Singhal R, Dheerendra S, Ralte P, Fischer J, Waseem M. Distal radius volar locking plates: does a variable angle locking system confer a clinical advantage? Acta Orthop Belg 2012;78 (03):309-316

46 Matschke S, Marent-Huber M, Audigé L, Wentzensen A; LCP Study Group. The surgical treatment of unstable distal radius fractures by angle stable implants: a multicenter prospective study. J Orthop Trauma 2011;25(05):312-317

47 Matschke S, Wentzensen A, Ring D, Marent-Huber M, Audigé L, Jupiter JB. Comparison of angle stable plate fixation approaches for distal radius fractures. Injury 2011;42(04):385-392

48 Mellstrand Navarro C, Ahrengart L, Törnqvist H, Ponzer S. Volar locking plate or external fixation with optional addition of Kwires for dorsally displaced distal radius fractures: a randomized controlled study. J Orthop Trauma 2016;30(04):217-224

49 Minegishi H, Dohi O, An S, Sato H. Treatment of unstable distal radius fractures with the volar locking plate. Ups J Med Sci 2011; 116(04):280-284

50 Osada D, Kamei S, Masuzaki K, Takai M, Kameda M, Tamai K. Prospective study of distal radius fractures treated with a volar locking plate system. J Hand Surg Am 2008;33(05):691-700

51 Phadnis J, Trompeter A, Gallagher K, Bradshaw L, Elliott DS, Newman KJ. Mid-term functional outcome after the internal fixation of distal radius fractures. J Orthop Surg 2012;7:4

52 Plate JF, Gaffney DL, Emory CL, et al. Randomized comparison of volar locking plates and intramedullary nails for unstable distal radius fractures. J Hand Surg Am 2015;40(06):1095-1101

53 Rampoldi M, Palombi D, Tagliente D. Distal radius fractures with diaphyseal involvement: fixation with fixed angle volar plate. J Orthop Traumatol 2011;12(03):137-143

54 Rozental TD, Blazar PE, Franko OI, Chacko AT, Earp BE, Day CS. Functional outcomes for unstable distal radial fractures treated with open reduction and internal fixation or closed reduction and percutaneous fixation. A prospective randomized trial. J Bone Joint Surg Am 2009;91(08):1837-1846

55 Sonderegger J, Schindele S, Rau M, Gruenert JG. Palmar multidirectional fixed-angle plate fixation in distal radius fractures: do intraarticular fractures have a worse outcome than extraarticular fractures? Arch Orthop Trauma Surg 2010;130(10):1263-1268

56 Souer JS, Ring D, Matschke S, Audige L, Maren-Hubert M, Jupiter J. Comparison of functional outcome after volar plate fixation with 2.4- $\mathrm{mm}$ titanium versus $3.5-\mathrm{mm}$ stainless-steel plate for extraarticular fracture of distal radius. J Hand Surg Am 2010;35(03): 398-405 
57 Sügün TS, Gürbüz Y, Özaksar K, Toros T, Kayalar M, Bal E. Results of volar locking plating for unstable distal radius fractures. Acta Orthop Traumatol Turc 2012;46(01):22-25

58 Takada N, Otsuka T, Yamada K, et al. Minimally invasive plate osteosynthesis for distal radius fractures with a palmar locking plate. Eur J Trauma Emerg Surg 2012;38(06):627-632

59 Tarallo L, Mugnai R, Zambianchi F, Adani R, Catani F. Volar plate fixation for the treatment of distal radius fractures: analysis of adverse events. J Orthop Trauma 2013;27(12):740-745

60 Vlček M, Jaganjac E, Pech J, Jonáš D, Kebrle R. Is minimally invasive application by intramedullary osteosynthesis in comparison with volar plating real benefit in the treatment of distal radius fractures? Bosn J Basic Med Sci 2014;14(02):81-88

61 Wei DH, Raizman NM, Bottino CJ, Jobin CM, Strauch RJ, Rosenwasser MP. Unstable distal radial fractures treated with external fixation, a radial column plate, or a volar plate. A prospective randomized trial. J Bone Joint Surg Am 2009;91(07):1568-1577

62 Wei XM, Sun ZZ, Rui YJ, Song XJ. Minimally invasive plate osteosynthesis for distal radius fractures. Indian J Orthop 2014; 48(01):20-24

63 Wichlas F, Haas NP, Disch A, Machó D, Tsitsilonis S. Complication rates and reduction potential of palmar versus dorsal locking plate osteosynthesis for the treatment of distal radius fractures. J Orthop Traumatol 2014;15(04):259-264

64 Wilcke MKT, Abbaszadegan H, Adolphson PY. Wrist function recovers more rapidly after volar locked plating than after external fixation but the outcomes are similar after 1 year. Acta Orthop 2011;82(01):76-81

65 Williksen JH, Frihagen F, Hellund JC, Kvernmo HD, Husby T. Volar locking plates versus external fixation and adjuvant pin fixation in unstable distal radius fractures: a randomized, controlled study. J Hand Surg Am 2013;38(08):1469-1476

66 Yu YR, Makhni MC, Tabrizi S, Rozental TD, Mundanthanam G, Day CS. Complications of low-profile dorsal versus volar locking plates in the distal radius: a comparative study. J Hand Surg Am 2011;36 (07):1135-1141

67 Zenke Y, Sakai A, Oshige T, et al. Clinical results of volar locking plate for distal radius fractures: conventional versus minimally invasive plate osteosynthesis. J Orthop Trauma 2011;25(07):425-431

68 Protopsaltis TS, Ruch DS. Volar approach to distal radius fractures. J Hand Surg Am 2008;33(06):958-965

69 Azzi AJ, Aldekhayel S, Boehm KS, Zadeh T. Tendon rupture and tenosynovitis following internal fixation of distal radius fractures: a systematic review. Plast Reconstr Surg 2017;139(03):717e-724e 